
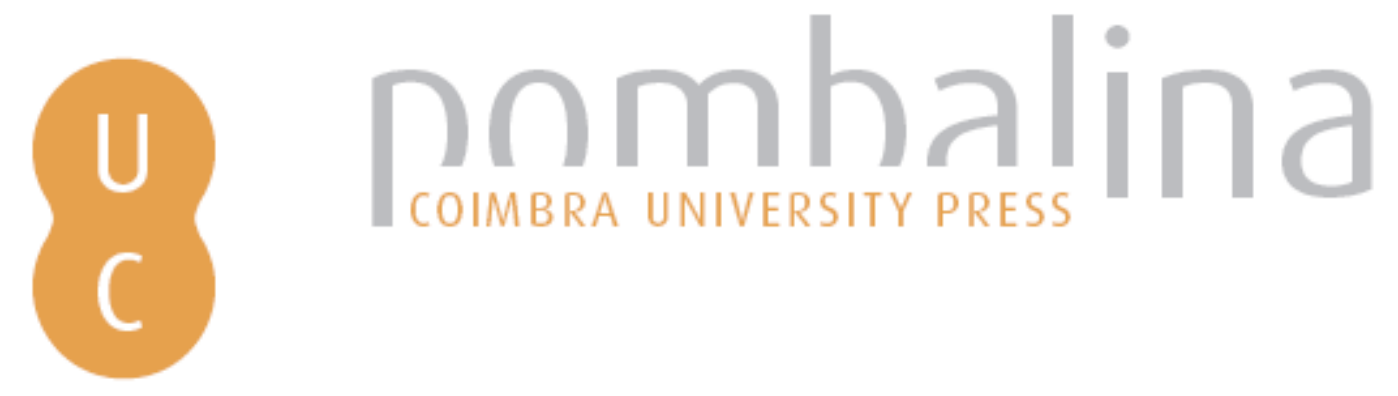

\title{
Bases de dados espaciais na gestão do combate a incêndios florestais. Estudo de caso: pontos de água (CentroW Portugal)
}

Autor(es): $\quad$ Lopes, Filipe Santana; Santos, Sara; Oliveira, André

Publicado por: Imprensa da Universidade de Coimbra

URL

persistente: URI:http://hdl.handle.net/10316.2/37070

DOI: $\quad$ DOI:http://dx.doi.org/10.14195/978-989-26-0983-6_17

Accessed : $\quad$ 26-Apr-2023 13:26:32

A navegação consulta e descarregamento dos títulos inseridos nas Bibliotecas Digitais UC Digitalis, UC Pombalina e UC Impactum, pressupõem a aceitação plena e sem reservas dos Termos e Condições de Uso destas Bibliotecas Digitais, disponíveis em https://digitalis.uc.pt/pt-pt/termos.

Conforme exposto nos referidos Termos e Condições de Uso, o descarregamento de títulos de acesso restrito requer uma licença válida de autorização devendo o utilizador aceder ao(s) documento(s) a partir de um endereço de IP da instituição detentora da supramencionada licença.

Ao utilizador é apenas permitido o descarregamento para uso pessoal, pelo que o emprego do(s) título(s) descarregado(s) para outro fim, designadamente comercial, carece de autorização do respetivo autor ou editor da obra.

Na medida em que todas as obras da UC Digitalis se encontram protegidas pelo Código do Direito de Autor e Direitos Conexos e demais legislação aplicável, toda a cópia, parcial ou total, deste documento, nos casos em que é legalmente admitida, deverá conter ou fazer-se acompanhar por este aviso.

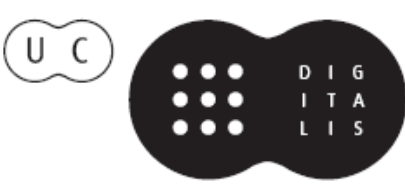




\section{$\forall$ \\ TAS DAS I JORNADAS LUSÓFONAS DE CIÊNCIAS E TECNOLOGIAS DE INFORMAÇÃO GEOGRÁFICA}

Editores

José Gomes dos Santos

Cidália Fonte

Rui Ferreira de Figueiredo

Alberto Cardoso

Gil Gonçalves

José Paulo Almeida

Sara Baptista 


\title{
A RTIGO 17
}

\section{BASES DE DADOS ESPACIAIS NA GESTÃO DO COMBATE A INCENDIOS FLORESTAIS - ESTUDO DE CASO: pontos de Água (CENTROW PORTUGAL)}

\author{
SANTANA LOPES, Filipe ${ }^{1}$; SANTOS, Sara ${ }^{2}$ E OLIVEIRA, André3
}

Instituto Superior de Estatística e Gestão de Informação da Universidade Nova de Lisboa, Campus de Campolide, 1070-312 Lisboa, Portugal.

1 tel: +351918426834; email: santana.gis.consulting@gmail.com

2 tel: +351933130487; email: sarasantos05@gmail.com

3 tel: +351 213828610; email: aoliveira@isegi.unl.pt

\section{RESUMO}

Este estudo tem como objetivo a construção de um modelo de base de dados espacial com recurso a software livre e de código fonte aberto que permita aceder, gerir e utilizar a informação relativa a todos os pontos de água disponíveis nos concelhos de Pombal, Soure e Leiria. Nesse sentido, efetuou-se a implementação da base de dados em PostgreSQL/PostGIS e procedeu-se à simulação de diversos cenários envolvendo análise espacial, com o intuito de se entender quais as informações relevantes a que os bombeiros podem recorrer face a um incêndio florestal. Os resultados obtidos demonstram a utilidade desta implementação para fornecer apoio aos bombeiros na gestão de cenários reais de combate a incêndios, e também a importância do recurso a dados de livre acesso regularmente atualizados, em particular OpenStreetMaps, nesta área de aplicação.

\section{PALAVRAS-CHAVE}

Bases de dados espaciais, Pontos de água, PostGIS, QuantumGIS, OpenStreetMaps 


\title{
SPATIAL DATABASES IN FOREST FIRE MANAGEMENT - CASE STUDY: WATER SPOTS (CENTRALW PORTUGAL)
}

\begin{abstract}
This study aims to provide a spatial database model based on free and open source software and using free access data such as OpenStreet Maps. The purpose of this database is to allow storage, management and spatial analysis of the information regarding water spots of three Portuguese mainland municipalities (Pombal, Soure and Leiria). This model was designed and implemented in a PostgreSQL/PostGIS database. Using also the popular free and open-source GIS package QuantumGIS, several spatial analysis scenarios were then tested to simulate its use in real-life firefighting situations. These simulations were focused on selecting and testing relevant spatial analysis needs firefighters face when confronted with decision-making in a forest fire situation. Results seem to demonstrate the potential benefits for firefighters of using regularly updated free and open access spatial data (particularly OpenStreetMaps) and software.
\end{abstract}

\section{KEYWORDS}

Spatial databases, Water spots, PostGIS, QuantumGIS, OpenStreetMaps

\section{INTRODUÇÃO}

Os incêndios florestais ocorrem todos os anos em Portugal e constituem a maior ameaça para as florestas portuguesas, com graves consequências ambientais e socioeconómicas (ZÊEZRE, 2010). Estes incêndios encontram-se entre as catástrofes que mais fustigam o nosso pais e para tal é importante a existência de um planeamento eficaz, tanto na prevenção como na atuação em casos de emergência, para que seja possível a rápida intervenção por parte das equipas de combate ao fogo. Existe informação que, obtida atempadamente e utilizada de forma correta, poderá ser muito útil no combate a incêndios florestais.

A utilização e importância dos Sistemas de informação geográfica (SIG) e das bases de dados espaciais que suportam estes sistemas, na área da proteção civil, gestão e mitigação de catástrofes são reforçadas por vários autores (ALTAN et al., 2010); (OOSTEROM et al., 2006). Já no domínio específico do combate aos fogos florestais, LYMBEROPOULOS et al. (1996) sugerem um sistema de informação para a gestão de fogos 
florestais baseado em SIG. Mais recentemente, SEN et al. (2011) apresentam um modelo de análise espacial com vista à seleção de localizações para postos de bombeiros, igualmente assente em SIG. SHORT (2014) apresenta uma base de dados espacial dos fogos florestais ocorridos nos Estados Unidos da América entre 1992 e 2011, chamando a atenção para a importância da disponibilidade de dados atualizados na gestão de operações e pesquisa neste sector.

No contexto dos fogos florestais, a disponibilidade de pontos de água para abastecimento dos meios de combate aos incêndios florestais é naturalmente um fator fundamental. O planeamento da rede constituída pelas localizações destes pontos não é isento de complexidade e necessita de ter conta diversas variáveis (ALMEIDA, 2007).

Uma base de dados espacial com informação sobre os pontos de águas é uma ferramenta importante no apoio ao combate e tomada de decisão, uma vez que as bases de dados espaciais representam uma das áreas mais dinâmicas dentro da gestão de dados, especialmente devido à grande importância dos Sistemas de informação geográfica (SIG) (OLAYA, 2011). O Sistema Nacional de Informação Geográfica (SNIG) realizou durante os anos de 1997 a 1999 um trabalho de cadastro e levantamento de pontos de água a nível nacional, com o objetivo de criar uma base de dados de todos os pontos. Esta base de dados permite fornecer apoio às equipas de combate a incêndios no que diz respeito ao abastecimento das suas viaturas e aeronaves (GRUPO C R I S E, 2010) e encontra-se disponível online na página do Sistema de Cartografia de Risco de Incêndio Florestal (SCRIF), mas não tem sido atualizada desde então.

\section{APRESEnTAÇÃo do TEMA}

Este estudo teve como objetivo principal o desenvolvimento de uma plataforma onde seja possível armazenar toda a informação relevante para a utilização dos pontos de águas pelos meios de combate aéreos, terrestres, ou ambos em caso de incêndio florestal. Para tal, a ideia base consistiu em partir dos dados disponíveis online na página do SCRIF e desenvolver uma base de dados mais completa, associando-lhe dados 
obtidos a partir do projeto OpenStreetMaps (OSM), o qual constitui um sistema colaborativo de mapeamento ao nível mundial, acessível a qualquer pessoa e atualizado diariamente nos servidores da GeoFabrik (GEOFABRIK, 2013).

$\mathrm{Na}$ implementação desta base de dados, pretendeu-se não apenas agrupar os dados necessários para a obtenção de respostas para a tomada de decisões no âmbito da estratégia de combate aos fogos florestais através do recurso a dados de livre acesso, mas também a aplicações de software livre e de código fonte aberto.

$\mathrm{Na}$ construção desta base de dados foram também tidas em consideração as normas para a identificação dos pontos de água para a utilização dos meios de combate a incêndios, de acordo com a Portaria $n^{\circ}$ 133/2007 de 26 de Janeiro.

Finalizada a base de dados, outro objetivo deste estudo prendeu-se com a simulação de consultas que permitam aos decisores elaborar uma estratégia de combate eficaz, quando confrontados com uma frente de fogo. Desta forma, é importante a seleção dos pontos de água com um volume superior ou igual a $10000 \mathrm{~m} 3$, para se estimar a viabilidade do abastecimento pelo meio de combate a incêndios. Para quem combate um incêndio, é igualmente relevante possuir informação acerca da acessibilidade aos pontos de água, no sentido de se entender se o ponto de água possui acesso aéreo, terrestre ou ambos. Outras informações pertinentes a ter em conta durante o combate a um incêndio consistem em perceber qual o meio aéreo mais próximo do ponto de água e delimitar a zona tampão de um ponto de água para a utilização de helicópteros (zona correspondente a um raio de ação de $1,5 \mathrm{~km}$ ). Sendo esta a zona de maior eficácia na utilização de um meio aéreo, o passo seguinte consiste na avaliação das manchas florestais abrangidas pela zona tampão.

No que respeita à área de estudo, a base de dados deverá vir a conter informação para todos os pontos de água existentes no país, mas no âmbito deste estudo a área de atuação limitou-se aos municípios de Soure, Pombal e Leiria, pertencentes à Nomenclatura Comum das Unidades Territoriais dois (NUT II) do Centro (IGFSE, 2014). No caso dos heliportos, foram incorporados apenas aqueles cuja localização se situa nos distritos de 
Coimbra e Leiria, onde se inserem os municípios em estudo (Figura 1).

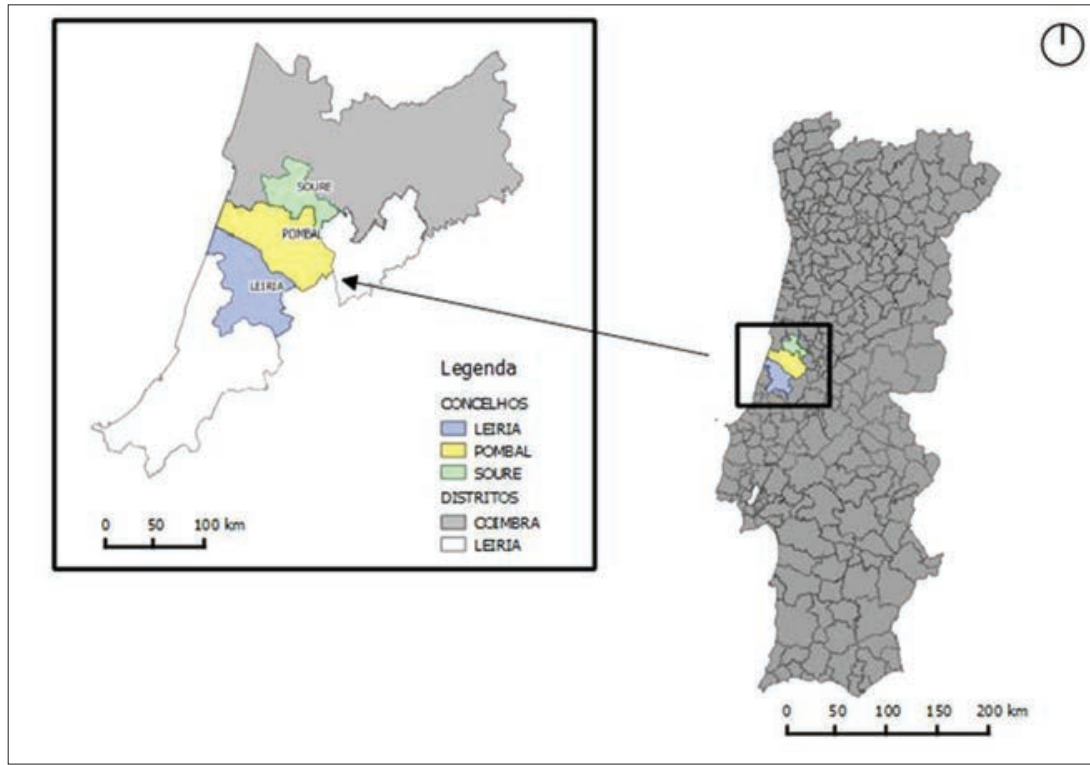

Figura 1 - Mapa da área de estudo

\section{OPÇÕES METODOLÓgICAS E APRESENTAÇÃo DOS DADOS}

A sequência de tarefas e opções metodológicas pode ser observada na Figura 2 (a azul). Para o desenvolvimento deste estudo optou-se pela utilização do Sistema Operativo (OS) Linux (Xubuntu, versão Saucy Salamander), visto que o programa osm2pgsq ${ }^{1}$ tem já bastante suporte e documentação para este OS, não sendo por outro lado garantido o correcto funcionamento desta função em ambiente Microsoft Windows (OPENSTREETMAP WIKI, 2013). A metodologia seguida divide-se nas tarefas de importação e preparação de dados em PostgreSQL/PostGIS e na execução de interrogações espaciais para simulação das consultas de apoio aos operacionais de combate aos fogos florestais, as quais serão apresentadas nos resultados.

\footnotetext{
${ }^{1}$ Programa incluído na extensão PostGIS e executado em linha de comandos que permite a conversão dos dados OSM para uma base de dados espacial alojada em PostgreSQL (OpenStreetMap Wiki, 2013).
} 


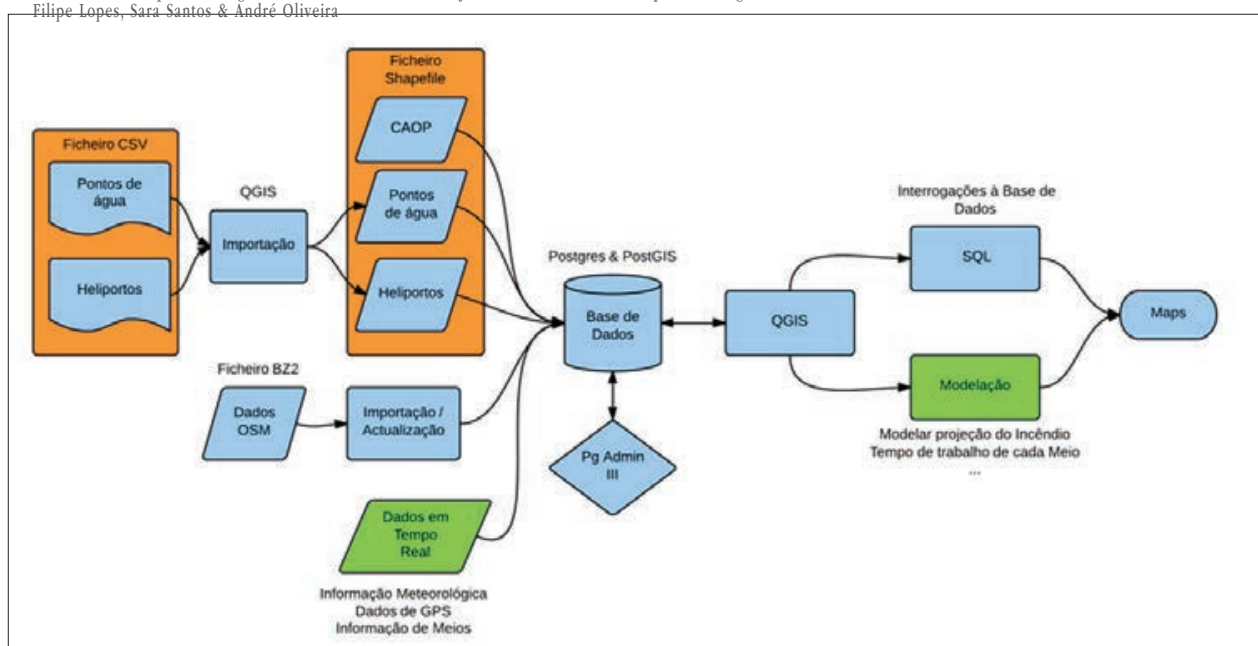

Figura 2 - Fluxograma da metodologia utilizada e planeada para futuros projetos

No que diz respeito às tarefas de Importação e preparação de dados em PostgreSQL/PostGIS, foi necessário numa primeira fase preparar os ficheiros shapefile para se conseguir a sua importação para a base de dados. A geração das tabelas relativas a pontos de água e heliportos foi efetuada através da importação de ficheiros comma-separated values (CSV) obtidos a partir do SCRIF. Os ficheiros da Carta Administrativa Oficial de Portugal (CAOP) foram obtidos na página da Direção Geral do Território em formato shapefile. Esta cartografia vem por defeito com os limites administrativos das freguesias, tendo sido necessário correr a função dissolve para a obtenção das áreas administrativas dos Concelhos e Distritos. Estes processos foram executados no software QuantumGIS (QGIS, 2013).

De seguida utilizou-se, em pgAdmin III (PGADMIN, 2013), a ferramenta PostGIS Shapefile and DBF Loader para importar os shapefiles para a base de dados, e foram estabelecidos os relacionamentos entre tabelas contendo dados espaciais e não espaciais, através de chaves primárias e estrangeiras. Para que os dados espaciais possam ser posteriormente visualizados em ambiente QGIS, é necessário definir-se previamente o sistema de coordenadas a que se referem, tendo-se aqui optado pelo sistema EPSG $^{2}$ 3763, correspondente ao sistema ETRS 3 89. Para tal, recorreu-se

\footnotetext{
2 EPSG - European Petroleum Survey Group.

3 ETRS - European Terrestrial Reference System.
} 
à seguinte função, executada a partir do terminal de linha de comandos psql (POSTGIS, 2013):

SELECT UpdateGeomtrySRID('table', 'the_geom', 3763)

$\mathrm{Na}$ importação dos dados OSM (cuja base da dados foi descarregada da página da Geofabrik com o formato .bz2) para a base de dados PostgreSQL/PostGIS foi necessário correr a seguinte função no terminal (OPENSTREETMAP WIKI, 2013) para permitir a sua posterior utilização no pgAdmin III:

$$
\begin{aligned}
& \text { sudo osm2pgsql -H localhost }-E 3763-s-U \text { user }-W \\
& -d \text { BDE_pa_osm -c portugal-latest.osm.bz2 }
\end{aligned}
$$

Para a realização de Interrogações sobre a base de dados PostgreSQL/ PostGIS a partir de QuantumGIS foi utilizada a ferramenta $D B$ Manager em ambiente QGIS, a qual permite fazer a ligação nos dois sentidos com a base de dados PostgreSQL/PostGIS, por outras palavras é possível efetuar consultas mas também criar novos dados que são automaticamente armazenados na base de dados.

\section{RESUlTADOS E DisCUSSÃo}

Apresentam-se de seguida as várias interrogações testadas, com o objetivo de simular a exploração da base de dados espacial implementada na fase anterior em situações de apoio à decisão no combate aos fogos florestais.

Assim, a primeira consulta consistiu em determinar quais os pontos possuem um volume de água igual ou superior a $10000 \mathrm{~m} 3$. Para tal, determinaram-se da tabela de pontos de água aqueles que satisfazem o critério escolhido e a tabela de freguesias foi também colocada na interrogação para se obter um melhor enquadramento geográfico para cada ponto de água, como se pode observar no seguinte bloco de código SQL:

SELECT pontos_agua.gid, pontos_agua.nome, pontos_agua.the_geom,"FREGUESIAS"."Freguesia", pontos_agua.gid_freguesia 


\section{FROM}

pontos_agua,"FREGUESIAS"

WHERE

pontos_agua.gid_freguesia = "FREGUESIAS".gid AND pontos_agua

volume $>=10000$;

O mapa resultante desta interrogação pode ser observado na Figura 3 em ambiente QGIS.

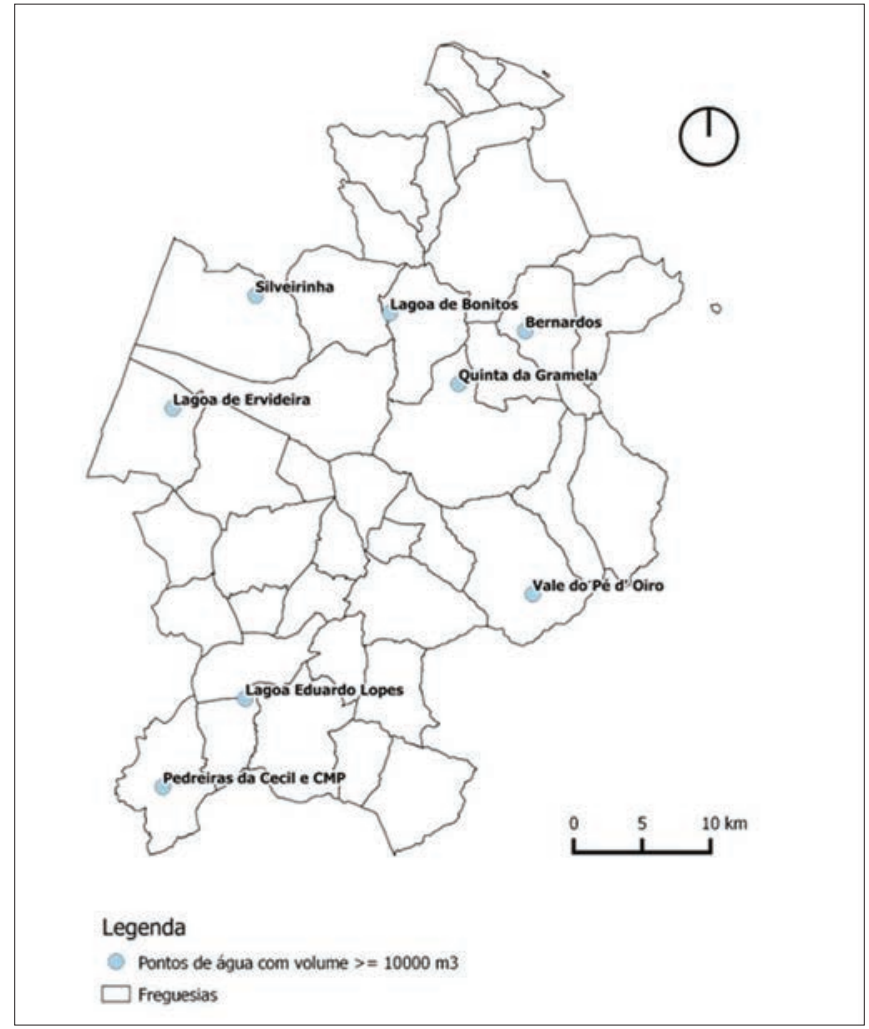

Figura 3 - Pontos de água com volume igual ou superior a $10000 \mathrm{~m} 3$

$\mathrm{Na}$ questão seguinte, pretendeu-se determinar quais os pontos de água da área em estudo possuem acesso misto (acesso por via terrestre e aérea). Para efetuar esta operação optou-se por criar uma vista, como se pode observar no bloco de código SQL correspondente:

CREATE VIEW acesso_view AS

SELECT pontos_agua.gid, pontos_agua.nome, pontos_agua.the_geom, acesso.tipo 


\section{FROM}

public.pontos_agua, public.acesso

WHERE

acesso.id_acesso $=$ pontos_agua.id_acesso AND acesso.id_acesso = 3;

O mapa resultante desta interrogação pode ser observado na figura 4 .

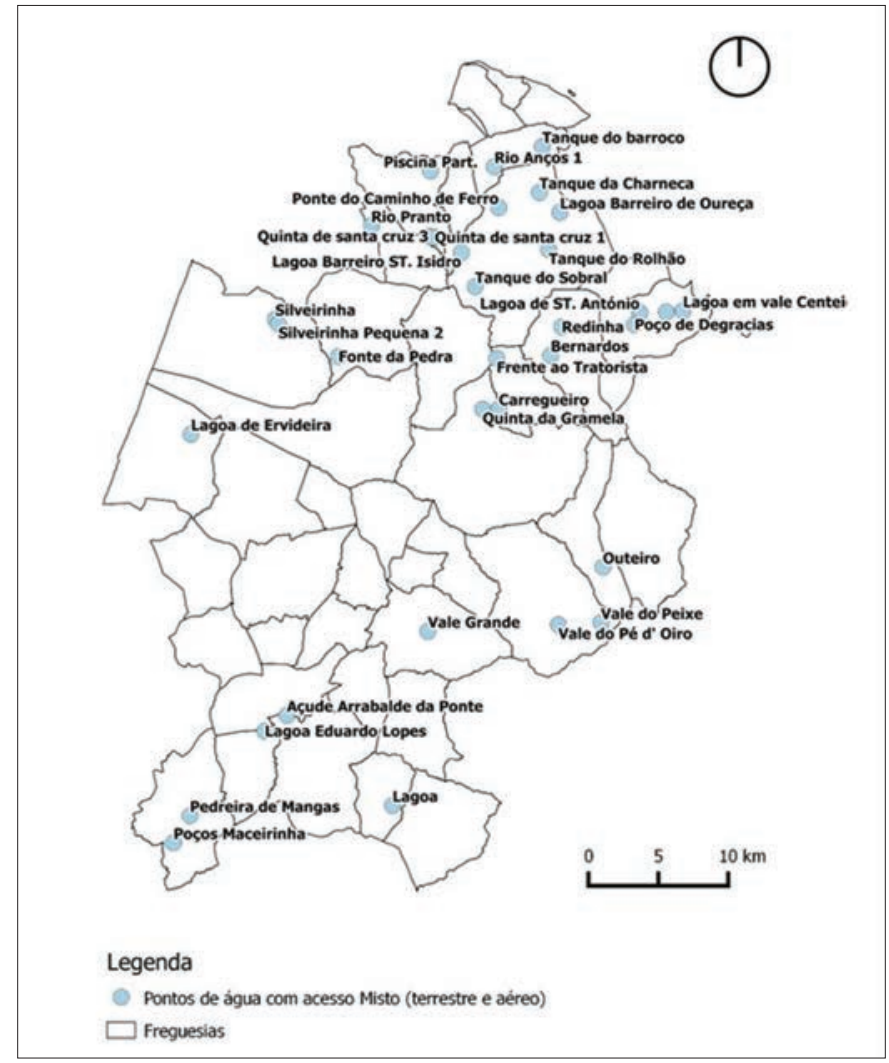

Figura 4 - Pontos de água de acesso misto

Noutra interrogação, determinou-se a distância entre um ponto de água previamente determinado (ponto "Borda do Rio") e os heliportos. Neste caso optou-se pela criação de duas vistas. Para a primeira utilizaram-se as tabelas de pontos de água e heliportos e empregou-se a função $S T \_$Distance para calcular a distância do ponto de água a cada heliporto, a qual foi de seguida ordenada por ordem crescente. A segunda vista foi gerada para facilitar a visualização gráfica da distância de cada heliporto ao ponto de água, utilizando a função ST_Buffer, como se pode observar 
nos dois blocos de código SQL seguintes:

CREATE VIEW dist2 AS

SELECT

pistas_6.nome, pontos_agua.gid, pontos_agua.the_geom, ST_Distance(pistas_6.the_geom, pontos_agua.the_geom) AS Distance FROM

public.pistas_6,public.pontos_agua

WHERE

pontos_agua.gid $=3$

ORDER BY Distance;

CREATE VIEW DIS5 AS

SELECT

nome,

st_buffer(the_geom, distance)

FROM

dist 2

ORDER BY distance DESC;

O mapa em QGIS resultante desta interrogação pode ser observado na figura 5.

Finalmente, simulou-se uma interrogação com o objetivo de determinar a área florestal coberta pela zona tampão de um ponto de água previamente escolhido ("Bernardos"). Esta interrogação é um exemplo das vantagens acrescentadas pela utilização de dados OSM.

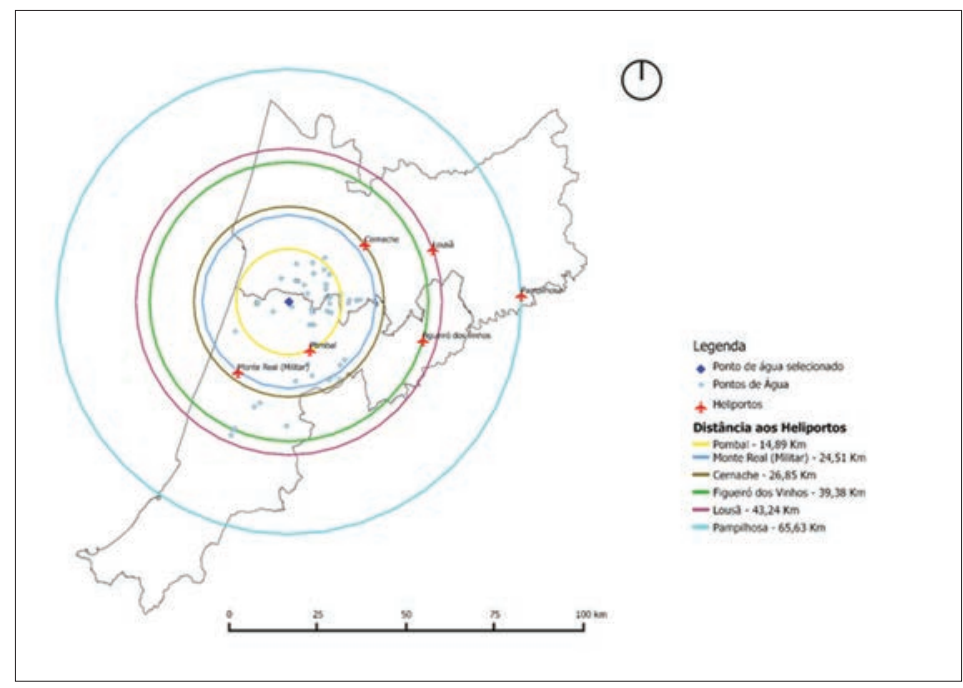

Figura 5 - Distâncias do ponto de água "Borda do Rio" aos heliportos 
Para se conseguir visualizar esta informação ao nível gráfico foi necessário adicionar ao bloco de código SQL a função "row_number() over () $A S$ id" que permite criar uma coluna nova contendo um identificador na interrogação efetuada (POSTGRESQL, 2013). Para além disto utilizou-se a função st_buffer para gerar a zona tampão do ponto de água e filtrou-se a tabela dos polígonos da OSM com a informação de floresta que se localiza dentro da zona tampão, o que foi feito com recurso á função $S T \_$WWithin, como se pode observar no seguinte bloco de código SQL:

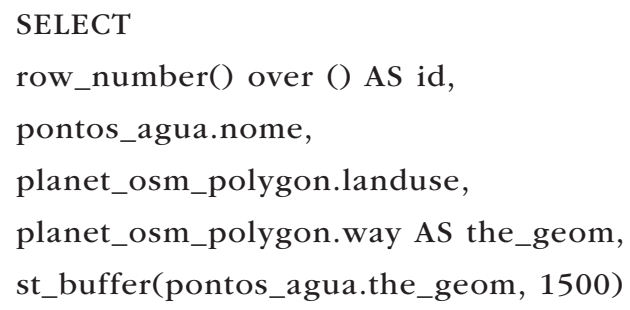

O mapa resultante desta interrogação pode ser observado na Figura 6.

Como se pode observar nas figuras apresentadas, após a construção da base de dados espacial com todos os dados necessários para tomar decisões face a um incêndio florestal, foi possível simular 4 cenários de apoio à decisão com obtenção dos resultados pretendidos. Por exemplo, no primeiro cenário (Figura 3) verificou-se que existem oito pontos de água com capacidade igual ou superior a $10000 \mathrm{~m} 3$. No segundo cenário (Figura 4) tornou-se possível visualizar os pontos de água onde o acesso poderá ser misto, sendo possível desta forma verificar qual o ponto de água mais acessível de acordo com a localização do incêndio. No terceiro cenário (Figura 5), a visualização da distâncias dos heliportos deste distrito ao ponto de água "Borda do Rio", permitiu verificar que o heliporto mais próximo seria o heliporto de Pombal, logo os meios aéreos deste 
heliporto seriam os primeiros a ser acionados. O último cenário (Figura 6) demonstra a utilização plena da base de dados espacial, recorrendo tanto a informação referente aos pontos de água como a dados OSM, tendo-se permitido detetar a existência de uma área apreciável de coberto vegetal/ florestal abrangido pela zona tampão (área de eficácia de utilização de um meio aéreo) do ponto de água "Bernardos".

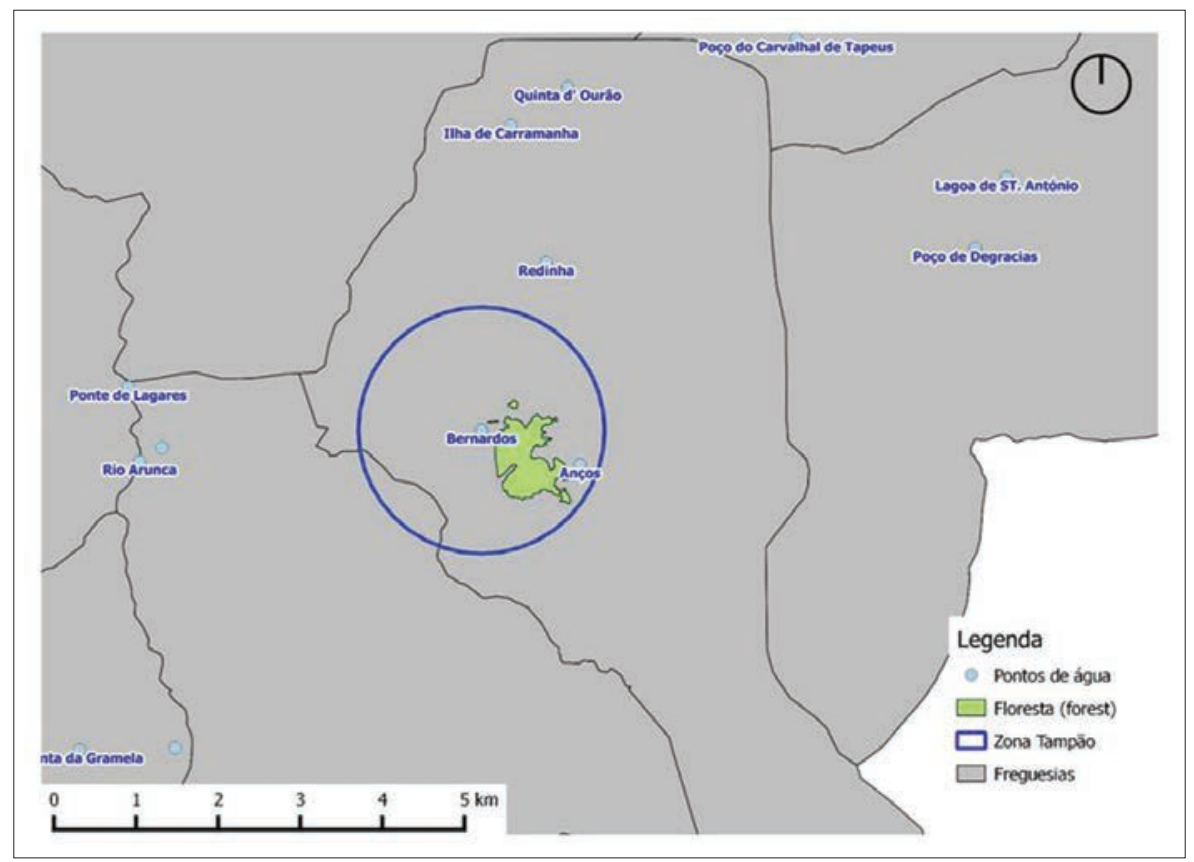

Figura 6 - Área florestal coberta pela zona tampão do ponto água "Bernardos"

\section{Conclusões}

A base de dados desenvolvida poderá constituir uma ferramenta importante para os bombeiros no apoio à tomada de decisão em operações de combate aos fogos florestais pois, como ilustrado pelos cenários operacionais ensaiados neste estudo, o recurso a um desenvolvimento deste tipo poderá trazer ganhos de eficácia e eficiência operacional na gestão e coordenação do combate a incêndios florestais por parte dos bombeiros. Poderá ser ainda interessante considerar a sua aplicação a outras áreas ligadas à proteção civil. 
Sob o ponto de vista das ferramentas, a implementação efetuada demonstra a utilidade da utilização de um sistema gestor de bases de dados espaciais como o PostgreSQL/PostGIS em conjunto com uma aplicação SIG como o QuantumGIS. Outra vantagem relevante para esta área de aplicação é a disponibilidade de dados espaciais gratuitos e atualizados (como é o caso do OpenStreetMaps), a qual traz a promessa de agilizar a gestão e aquisição de informação essencial por parte dos bombeiros, mais ainda no atual cenário de crise económica.

Numa perspetiva de futuro, seria interessante a inclusão de dados dinâmicos na base de dados PostgreSQL/PostGIS, como por exemplo dados referentes à evolução das localizações dos meios de combate e logística através da ligação da base de dados a um sistema de posicionamento global (GPS), bem como dados acerca do estado de cada meio e o seu tempo de trabalho. Desta forma tornar-se-ia possível monitorizar quase em tempo real o evoluir do cenário de combate ao fogo, garantindo desta forma uma melhor eficiência. Outra possibilidade seria a modelação da progressão de um incêndio florestal combinando dados dinâmicos relativos a variáveis meteorológicas com dados estáticos referentes ao relevo obtido através da inclusão de um modelo digital de terreno da área afetada pelo fogo. Estes são apenas alguns exemplos representativos do grande potencial e opções futuras, encontrando-se também assinalada a verde na Figura 2 a sua incorporação na metodologia geral deste estudo.

\section{BIBLIOGRAFIA}

ALMEIDA, Rui (2007) - "O abastecimento de água em combate a incêdios e o planeamento da Rede de Pontos de Água”, Serviço Nacional de Bombeiros e Proteção Civil Disponível online no endereço url: http:// naturlink.sapo.pt/Natureza-e-Ambiente/Agricultura-e-Floresta/ content/O-abastecimento-de-agua-em-combate-a-incendios-e-o-planeamento-da-Rede-de-Pontos-de-agua?bl=1\&viewall=true\#Go_1 (acedido em 20 Novembro, 2013)

ALTAN et al. (2010) - Geoinformation for Disaster and Risk Management - Examples and Best Practices, Joint Board of Geospatial Information Societies

GEOFABRIK (2013) - Download OpenStreetMap data for this region: Europe. Disponível online no endereço url: http://download.geofabrik.de/europe. 
html (acedido em 10 Novembro, 2013)

GRUPO C R I S E (2010) - "Rede de Informação de Situações de Emergência". Disponível online no endereço url: http://scrif.igeo.pt/ (acedido em 2 Novembro, 2013)

IGFSE (2014) - "Nomenclatura das unidades territoriais para fins estatísticos (NUTS)” Disponível online no endereço url: http://www.igfse.pt/st_glossario asp?startAt=2\&categoryID=309 (acedido em 10 Fevereiro, 2014)

LYMBEROPOULOS et al. (1996) - "A GIS-Based Forest Fire Management Information System”. Disponível online no endereço url: http://www.dblab.ece.ntua.gr/ pubs/uploads/TR-1996-2.pdf (acedido em 25 Novembro, 2013)

OLAYA, Victor (2011) - "Sistemas de Informacion Geográfica". Disponível online no endereço url: sextante.googlecode.com/files/Libro_SIG.pdf (acedido em 23 Novembro, 2013)

OOSTEROM et al. (2006) - Geo-information for Disaster Management, Springer

OPENSTREETMAP WIKI (2013) - Disponível online no endereço url: http://wiki. openstreetmap.org/wiki/Develop (acedido em 19 Novembro, 2013)

PGADMIN (2013) - "PostgreSQL administration and management tools". Disponível online no endereço url: http://www.pgadmin.org/ (acedido em 11 Novembro, 2013)

Portaria n. ${ }^{\circ}$ 133/2007 de 26 de Janeiro. Diário da República, $1 .^{a}$ série - N. $^{\circ} 19$, 26 de Janeiro de 2007. Lisboa. Portugal

POSTGIS (2013) - "Spatial and Geographic Objects for PostgreSQL". Disponível online no endereço url: http://postgis.net/ (acedido em 11 Novembro, 2013)

QGIS (2013) - "Welcome to the QGIS project!". Disponível online no endereço url: http://www.qgis.org/en/site/index.html (acedido em 2 Novembro, 2013)

SEN et al. (2011) - A GIS APPROACH TO FIRE STATION LOCATION SELECTION. Disponível online no endereço url: http://www.isprs.org/proceedings/2011/ Gi4DM/PDF/OP80.pdf (acedido em 30 Novembro, 2013)

ZÊZERE, José L. et al. (2008) - Plano Regional de Ordenamento do Território do Oeste e Vale do Tejo. Disponível online no endereço url: http://consulta-protovt. inescporto.pt/plano- regional/relatorio-do-plano/relatorios-sectoriais-de-caracterizacao-e- diagnostico/Sectorial_Riscos_Proteccao_Civil.pdf (acedido em 25 Novembro, 2013) 
Série Documentos

Imprensa da Universidade de Coimbra

Coimbra University Press

2015

- U M

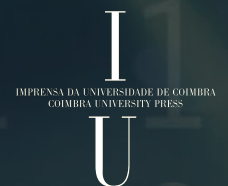

